\begin{tabular}{|c|c|}
\hline 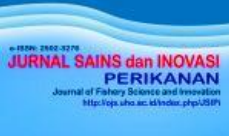 & $\begin{array}{c}\text { JURNAL SAINS dan INOVASI PERIKANAN } \\
\text { Journal of Fishery Science and Innovation } \\
\text { e-ISSN: } 2502-3276\end{array}$ \\
\hline जबाम & $\begin{array}{c}\text { Vol. 3, No. 2, 39-44, Juli } 2019 \\
\text { http://ojs.uho.ac.id/index.php/JSIPi }\end{array}$ \\
\hline
\end{tabular}

\title{
Hasil Tangkapan Utama dan Tangkapan Sampingan Bagan Rambo di Perairan Teluk Lasolo Kabupaten Konawe Utara
}

\section{The Main Catch and By Catch of Bagan Rambo in Lasolo Bay of Konawe Utara Regency}

\author{
Zul Chaidir ${ }^{1 *)}$, La Sara $^{2)}$, Naslina Alimina ${ }^{3)}$ \\ ${ }^{1)}$ Program Studi Ilmu Perikanan Pascasarjana Univ. Halu Ole, Kendari Indonesia \\ 2) Program Studi Manajemen Sumberdaya Perairan,Fakultas Perikanan dan Ilmu Kelautan Universitas Halu Oleo, Kendari Indonesia \\ 3) Program Studi Pemanfaatan Sumberdaya Perikanan Fakultas Perikanan dan Ilmu Kelautan Universitas Halu Oleo, Kendari Indonesia \\ Corresponding author ${ }^{*)}$ : zchaidir99@gmail.com,
}

\begin{abstract}
The aim of this study was analyze the main catch and by catch of bagan rambo in Lasolo Bay of Konawe Utara regency. This study was done about 2 months (on January-February) 2019 by survey method. The taking of fish samples was carried out as many as 30 trips using bagan rambo by the sampling method was stratified random sampling. All samples obtained were separated by type then measurements of the length and weight of each species were caught. The composition of the overall catch species as many as 37.881 individuals consisted of 50 species, each of 46 species of fish from 24 families and 2 groups of non fish each of 3 species of molluscs and 1 species of crustaceans. The main catch was dominate by anchovy (Stolephorus commersoni) as much as $73.83 \%$, by catch useable as much as $26.13 \%$ consisting of 45 species, and by catch discarded as much as $0.026 \%$ consisting of 3 pufferfish species (Tetraodon sp.).
\end{abstract}

Key words: catch composition, main catch, by catch, bagan rambo

\begin{abstract}
ABSTRAK
Tujuan penelitian ini adalah untuk mengetahui hasil tangkapan utama dan tangkapan sampingan bagan rambo di perairan Teluk Lasolo Kabupaten Konawe Utara. Waktu pelaksanaan penelitian selama 2 bulan (JanuariFebruari) 2019 dengan metode survei. Pengambilan sampel ikan dilakukan sebanyak 30 trip menggunakan alat tangkap bagan rambo dengan metode sampling yang digunakan adalah stratified random sampling. Seluruh sampel yang diperoleh dipisahkan berdasarkan jenis kemudian dilakukan pengukuran panjang dan bobot tubuh masing-masing jenis yang tertangkap. Komposisi jenis hasil tangkapan secara keseluruhan sebanyak 37.881 individu terdiri dari 50 jenis, masing-masing 46 spesies ikan dari 24 famili dan 2 kelompok non ikan masingmasing 3 spesies mollusca dan 1 spesies crustacea. Hasil tangkapan utama didominasi oleh ikan teri (Stolephorus commersoni) sebanyak $73,83 \%$, tangkapan sampingan yang masih bisa dimanfaatkan sebanyak $26,13 \%$ terdiri dari 45 spesies, dan yang tidak dapat dimanfaatkan/dibuang ke laut sebanyak 0,026\% terdiri dari 3 spesies ikan buntal (Tetraodon sp.).
\end{abstract}

Kata Kunci: komposisi hasil tangkapan, tangkapan utama, tangkapan sampingan, bagan rambo

DOI: http://dx.doi.org/10.33772/jspi.v3n2

\section{PENDAHULUAN}

Salah satu alat tangkap yang banyak digunakan dalam penangkapan ikan di perairan Teluk Lasolo
Kabupaten Konawe Utara adalah bagan rambo. Bagan merupakan salah satu alat tangkap ikan yang dalam pengoperasiannya menggunakan bantuan cahaya (light fishing) (Hasan, 2008; Yuda et al., 
40 Zul Chaidir et al.

JURNAL SAINS dan INOVASI PERIKANAN / Journal of Fishery Science and Innovation

Vol. 3, No. 2, 39-44, Juli 2019

2012). Secara umum, deskripsi alat tangkap bagan terdiri dari kapal, rangka bagan, bingkai jaring dan jaring, dan rumah bagan.

Pada umumnya, alat tangkap ini ditujukan untuk menangkap ikan teri (Stolephorus sp.). Namun, beberapa jenis ikan lain juga ikut tertangkap, seperti ikan tembang (Sardinella sp.), ikan selar (Selaroides sp.), ikan kembung (Rastrelliger sp.), ikan layang (Decapterus sp.), dan cumi-cumi (Loligo sp.). Beberapa jenis ikan tersebut dimanfaatkan (useable) dan juga beberapa jenis lainnya dibuang kembali ke laut (discarded).

Permasalahan dari sebagian besar alat tangkap yang dioperasikan pada perairan demersal adalah ketidakselektifan alat tangkap terhadap hasil tangkapan karena ukuran mata jaring. Ada beberapa hal yang menjadi perhatian mengenai proses pembuangan by catch (Saila, 1983; Gulland dan Rothschild, 1984) yaitu : (1) pembuangan makanan potensial yang baik; (2) berdampak buruk terhadap lingkungan dasar perairan; dan (3) mengurangi stok dari target spesies dan non-target spesies yang komersial.

Alat tangkap ikan yang baik mengacu pada Code of Conduct Responsible Fisheries (CCRF) yang merupakan pedoman pelaksanaan kegiatan perikanan secara bertanggung jawab. Pedoman ini memberi jaminan pemanfaatan sumberdaya laut yang lestari dan berkelanjutan (Sumardi et al., 2014). Pengunaan alat tangkap ramah lingkungan yang sesuai dengan CCRF harus sesuai dengan kriteria tertentu, antara lain memiliki selektivitas tinggi, hasil tangkapan minimum terbuang dan harus memberikan dampak minimum terhadap keanekaragaman sumberdaya hayati (biodiversity) (Firdaus et al., 2017).

Saat ini pengoperasian bagan rambo merupakan salah satu alat tangkap yang efektif digunakan oleh nelayan dalam menangkap ikan berdasarkan pengamatan di lapangan. Namun saat ini belum ada informasi mengenai hasil tangkapan utama dan tangkapan sampingan bagan rambo di perairan Kabupaten Konawe Utara. Tujuan penelitian ini adalah untuk mengetahui hasil tangkapan utama dan tangkapan sampingan bagan rambo di perairan Kabupaten Konawe Utara.

\section{METODE PENELITIAN}

Penelitian ini dilaksanakan selama 2 bulan penelitian (Januari-Februari 2019) di perairan Teluk
Lasolo Kabupaten Konawe Utara (Gambar 1) dengan metode survei. Pengambilan sampel ikan dilakukan sebanyak 30 trip menggunakan alat tangkap bagan Rambo sejumlah 10 unit. Spesifikasi alat tangkap bagan rambo yang digunakan disajikan pada Tabel 1 .

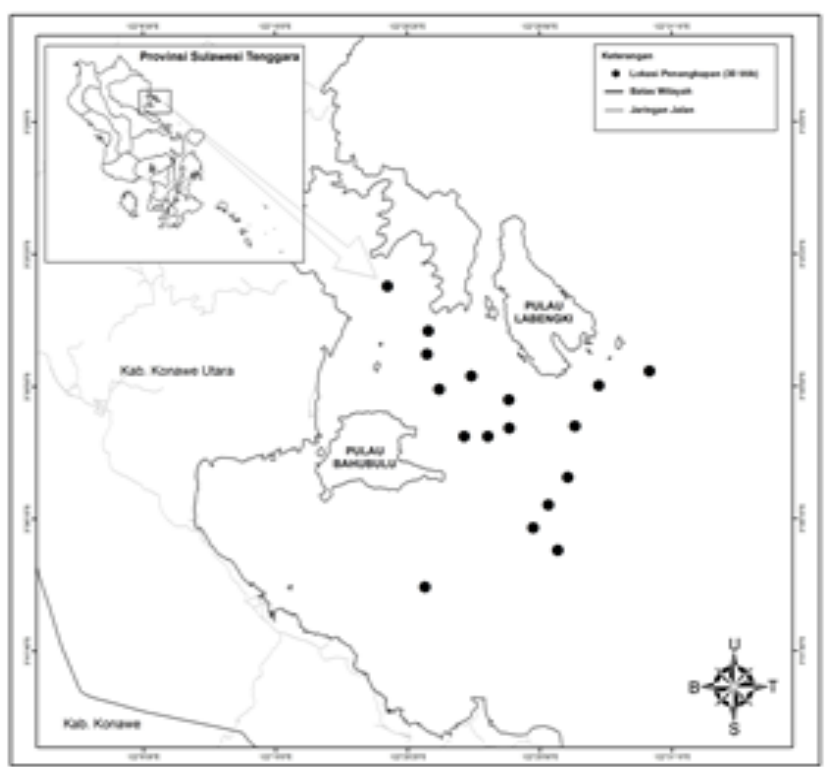

Gambar 1. Peta lokasi penelitian Teluk Lasolo Kabupaten Konawe Utara

Tabel 1. Spesifikasi kisaran ukuran sepuluh unit alat tangkap bagan rambo yang digunakan.

\begin{tabular}{clcc}
\hline No & \multicolumn{1}{c}{ Komponen } & Satuan & Ukuran \\
\hline 1. & Kapasitas kapal & $\mathrm{GT}$ & $10-27$ \\
2. & Panjang kapal & $\mathrm{M}$ & $17-27$ \\
3. & Lebar kapal & $\mathrm{M}$ & $2,0-2,8$ \\
4. & Tinggi kapal & $\mathrm{M}$ & $1,9-3,0$ \\
5. & Panjang sayap & $\mathrm{M}$ & $26-30$ \\
6. & Lebar sayap & $\mathrm{M}$ & $26-30$ \\
7. & Panjang jaring & $\mathrm{M}$ & $26-30$ \\
8. & Lebar jaring & $\mathrm{M}$ & $26-30$ \\
9. & Tinggi jaring & $\mathrm{M}$ & $11-26$ \\
10. & Jumlah lampu & $\mathrm{Unit}$ & $20-40$ \\
11. & Besaran daya & $\mathrm{Watt}$ & $650-30000$ \\
12. & Dinamo listrik & $\mathrm{Kw}$ & $30-50000$ \\
13. & Kapal pengantar & $\mathrm{GT}$ & $2-5$ \\
14. & Panjang kapal & $\mathrm{M}$ & $12-19$ \\
& pengantar & & \\
15. & Lebar kapal pengantar & $\mathrm{M}$ & $1,5-2,37$ \\
16. & Tinggi kapal pengantar & $\mathrm{M}$ & $0,70-1,5$ \\
17. & Jumlah kapal pengantar & $\mathrm{Unit}$ & $1-2$ \\
18. & Kapasitas mesin kapal & $\mathrm{PS}$ & $100-135$ \\
& pengantar & & \\
\hline
\end{tabular}


Metode pengambilan sampel yang digunakan yaitu stratified random sampling (Cohran, 1991). Data mengenai target spesies dan non-target spesies yang dikumpulkan meliputi jenis ikan, panjang tubuh, bobot dan jumlah setiap jenis ikan. Jenis-jenis ikan yang tertangkap diidentifikasi menggunakan buku identifikasi Allen et al (1999). Hasil tangkapan sampingan (by catch) terdiri dari ikan yang dapat dimanfaatkan (useable) dan tidak dapat dimanfaatkan atau di buang kembali ke laut (discarded) (Alverson et al., 1994; Purbayanto et al., 2004; Wahyu, 2008). Tingkat by catch dihitung dengan formula sebagai berikut (Akiyama, 1997) :

Persentasi By catch $=\frac{\sum \text { by catch }}{\text { Total Tangkapan }} \times 100 \%$

dimana,

S bycatch : Jumlah individu hasil

tangkapan sampingan (individu).

Total tangkapan : Jumlah individu semua jenis ikan /jumlah total individu setiap pengambilan sampel (ind).

\section{HASIL DAN PEMBAHASAN}

\section{Hasil}

Komposisi jenis hasil tangkapan bagan rambo yang diperoleh di perairan Teluk Lasolo Kabupaten Konawe Utara disajikan dalam Gambar 2. Persentasi hasil tangkapan utama dan sampingan bagan rambo yang diperoleh di perairan Teluk Lasolo Kabupaten Konawe Utara disajikan pada Gambar 3. Komposisi ukuran panjang dan bobot hasil tangkapan bagan rambo di perairan Teluk Lasolo Kabupaten Konawe Utara masing-masing disajikan pada Gambar 4 dan Gambar 5.

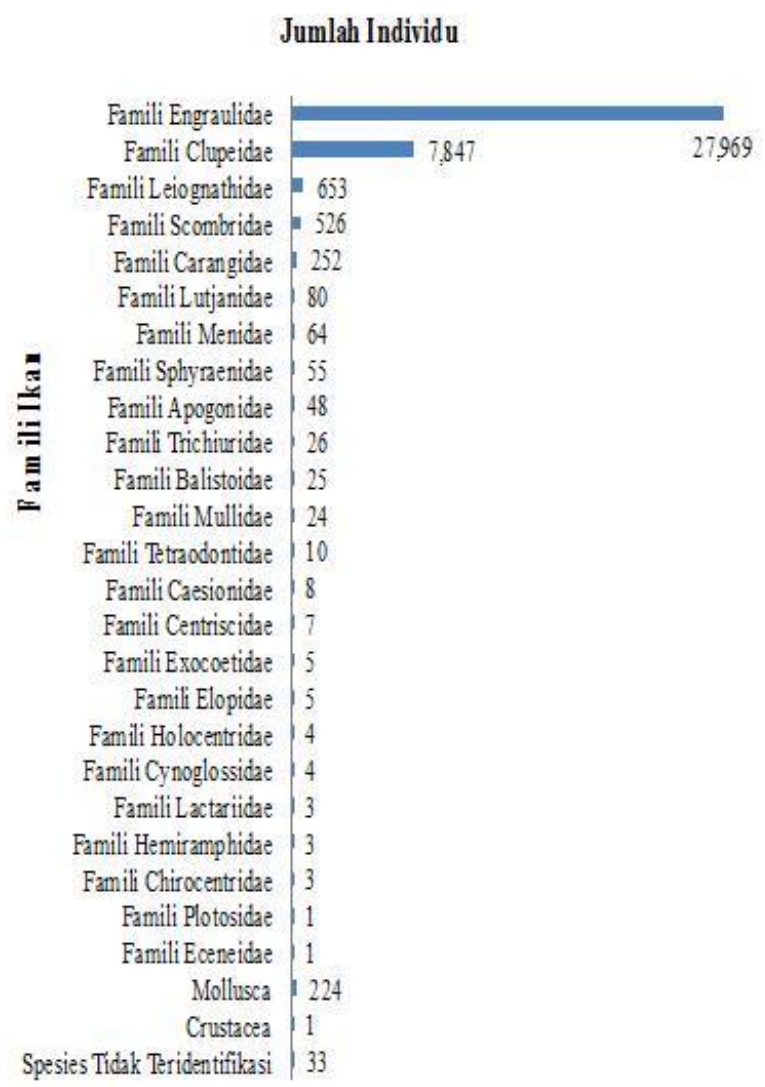

Gambar 2. Komposisi jenis hasil tangkapan berdasarkan kelompok famili

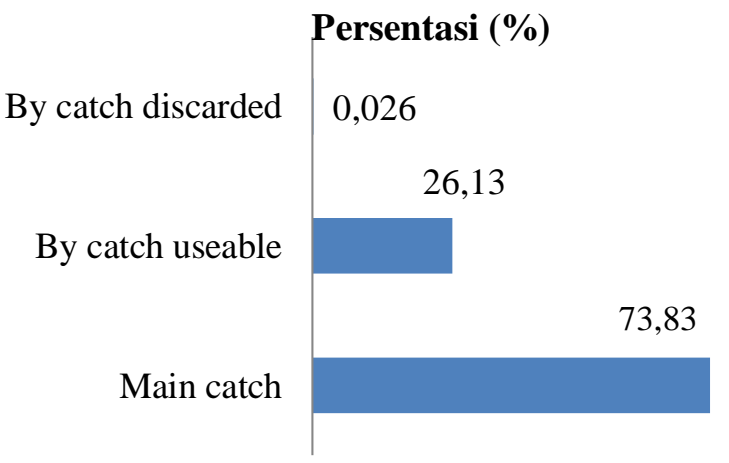

Gambar 3. Persentasi hasil tangkapan utama (main catch) dan sampingan (by catch) bagan rambo 
42 Zul Chaidir et al.

JURNAL SAINS dan INOVASI PERIKANAN / Journal of Fishery Science and Innovation

Vol. 3, No. 2, 39-44, Juli 2019

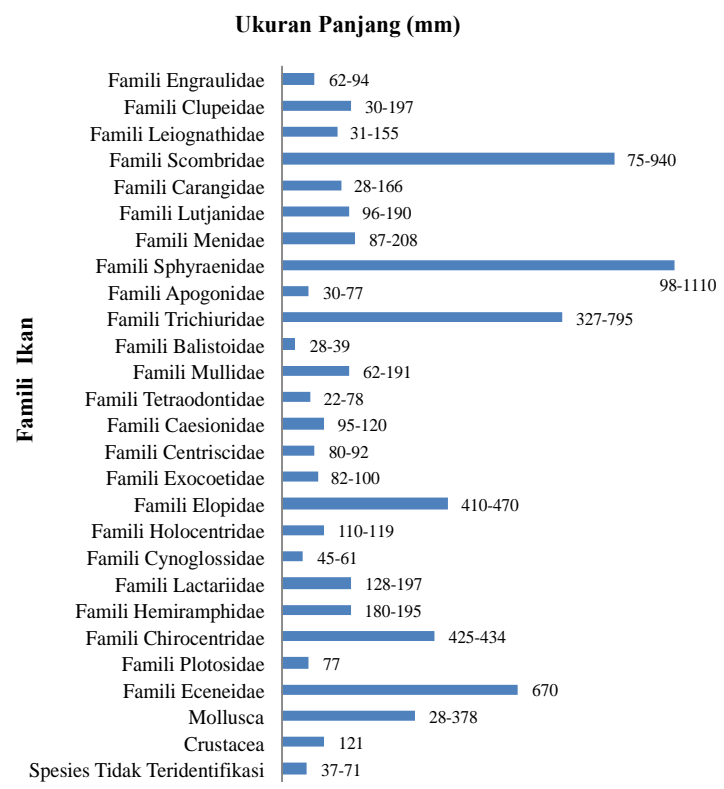

Gambar 4. Komposisi ukuran panjang hasil tangkapan berdasarkan kelompok famili

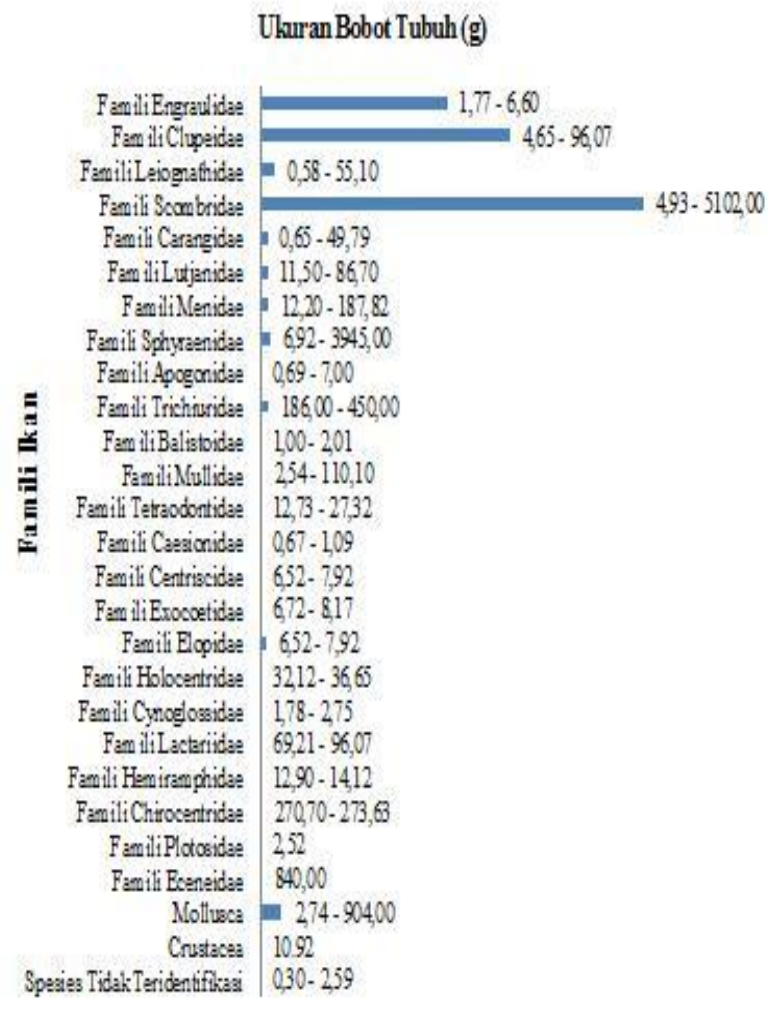

Gambar 5. Komposisi ukuran bobot hasil tangkapan berdasarkan kelompok famili

\section{Pembahasan}

Komposisi jenis hasil tangkapan bagan rambo di perairan Teluk Lasolo Kabupaten Konawe Utara secara keseluruhan berjumlah 37.881 individu yang terdiri dari 50 spesies, masing-masing 46 spesies ikan dari 24 famili dan 2 kelompok non ikan masingmasing 3 spesies mollusca dan 1 spesies crustacea. Hasil tangkapan bagan rambo selama 30 trip penelitian didominasi oleh ikan teri (Stolephorus commersoni) dari total hasil tangkapan. Assir et al. (2017) juga dalam penelitiannya di Laut Flores Kepulauan Selayar menemukan frekuensi terbanyak hasil tangkapan adalah ikan teri (Stolephorus sp). Nelwan et al. (2015) dalam penelitiannya menyatakan bahwa komposisi jenis hasil tangkapan bagan rambo di perairan Kabupaten Sinjai didominasi oleh ikan teri (Stolephorus sp) sebanyak $32,98 \%$. Beberapa jenis ikan lain yang sama tertangkap dalam penelitian ini, antara lain ikan alualu (Sphyraena qenie), ikan buntal (Lagocephalus sp. dan Arothron sp.), ikan kuwe putih (Caranx sp.), cumi-cumi (Loligo sp.), julung-julung (Hemirhampus far), ikan kembung (Rastrelliger sp.), ikan bete-bete (Mene maculata), ikan parang-parang (Chirocentus dorab), ikan peperek (Leiognathus equulus), ikan selar kuning (Selaroides leptolepsis), sotong (Sepia sp.), ikan talang-talang (Scomberoides commersonnianus), ikan tenggiri (Scomberomurus commerson), dan ikan beseh merah (Apogon sp.).

Salah satu faktor yang mempengaruhi banyaknya jumlah ikan teri yang tertangkap adalah berdasarkan tingkah lakunya ikan teri bersifat pelagik dan hidup bergerombol pada daerah pesisir, sering melakukan migrasi sehingga keberadaannya sangat dipengaruhi oleh musim. Luasunaung (2011) dalam penelitiannya menyatakan bahwa ketika musim barat (DesemberFebruari) dan musim timur (Agustus-September) ikan teri lebih sedikit tertangkap dibanding pada musim pancaroba yang merupakan musim puncak ikan teri tertangkap.

Hasil tangkapan utama (main catch) bagan rambo di perairan Teluk Lasolo Kabupaten Konawe Utara adalah ikan teri (Stolephorus commersoni) dengan persentasi $73,92 \%$. Hasil tangkapan sampingan bagan rambo yang dapat dimanfaatkan kembali (by catch useable) secara keseluruhan sebesar $26,05 \%$, sedangkan yang tidak dimanfaatkan dan dibuang ke laut (by catch discarded) yaitu sebanyak $0,03 \%$. Hasil tangkapan sampingan yang 
dimanfaatkan tersebut juga dikomersilkan atau dimanfaatkan sendiri oleh nelayan.

Takril (2008) menyatakan dalam penelitiannya bahwa hasil tangkapan utama bagan perahu di perairan Polewali adalah ikan teri (Stolephorus spp.), ikan kembung (Rastrelliger sp.), dan ikan layang (Decapterus ruselli), sehingga spesies lainnya tergolong hasil tangkapan sampingan. Tirtana (2016) menyatakan bahwa total hasil tangkapan selama penelitian berjumlah 13.012 individu yang terdiri dari 11 spesies. Hasil tangkapan utama didominasi oleh ikan tongkol (Auxis rochei) sebanyak 61\%, ikan teri (Stolephorus sp) sebanyak 24\%, dan cumi-cumi (Loligo sp.) sebanyak 13\%. Hasil tangkapan sampingan terdiri dari 8 spesies ikan, 2 di antara spesies tersebut tidak dapat diidentifikasi sebanyak $1 \%$ dan 6 spesies lainnya masing-masing adalah ikan lemuru (Sardinella lemuru) sebanyak $0,78 \%$, ikan sembulak (Sardinella sp.) sebanyak 0,46\%, ikan kembung (Rastrilliger sp) sebanyak $0,05 \%$, ikan layang (Decapterus russeli) sebanyak 0,05\%, ikan layang (D. macrosoma) sebanyak $0,03 \%$, dan ikan terbang (Hirundichthys oxycephalus) sebanyak $0,01 \%$. Berdasarkan komposisi hasil tangkapan tersebut yang bersumber dari berbagai penelitian dapat dikatakan bahwa alat tangkap bagan rambo memiliki hasil tangkapan sampingan yang bervariasi dan memiliki nilai jual yang cukup ekonomis, bahkan bisa melampaui harga jual tangkapan utama.

Komposisi ukuran panjang dan bobot hasil tangkapan bagan rambo di perairan Teluk Lasolo Kabupaten Konawe Utara bervariasi bergantung pada jenis ikan yang tertangkap, yakni komposisi ukuran panjang dan bobot terbesar dan terkecil masingmasing pada ikan barakuda (Sphyraena barracuda) Famili Sphyraenadae dengan ukuran panjang bobot $1110 \mathrm{~mm}$ dan 3945,00 g dan ikan buntal (Arothron sp.) Famili Tetraodontidae dengan ukuran panjang bobot $22 \mathrm{~mm}$ dan 2,14 g. Komposisi ukuran tersebut salah satunya dipengaruhi oleh ragam jenis ikan yang tertangkap. Jenis ikan yang mencapai panjang maksimum lebih cepat, seperti ikan-ikan pelagis kecil memiliki distribusi ukuran panjang yang lebih kecil dibanding dengan ikan-ikan pelagis besar atau ikan demersal. Direktorat Jenderal Perikanan Tangkap (2005) menyatakan bahwa ikan pelagis kecil mempunyai ukuran panjang maksimum ikan dewasa kurang dari $1000 \mathrm{~mm}$, sedangkan ikan pelagis besar mempunyai ukuran panjang maksimum antara $1000 \mathrm{~mm}$ hingga lebih dari $2500 \mathrm{~mm}$.
Berdasarkan komposisi ukuran yang diperoleh, bagan rambo mampu menangkap ikan-ikan yang masih berukuran kecil atau belum dewasa karena mesh size yang digunakan adala $0,5 \mathrm{~cm}$. Hal ini didukung dengan penelitian lain, yaitu Sudirman et al (2012) menyatakan bahwa performens selektivitas alat tangkap bagan sangat buruk, baik dilihat dari ukuran maupun jenis ikan yang tertangkap. Hal ini ditunjukkan dengan sempitnya batas ukuran antara ikan yang lolos dan ikan yang tertangkap. Dalam penelitian ini ukuran terkecil ikan yang tertangkap yaitu ikan buntal (Arothron $s p$ ) pada ukuran $22 \mathrm{~mm}$, cumi-cumi (Loligo $s p$ ) dan ikan pakol (Abalistes stellaris) pada ukuran $28 \mathrm{~mm}$, dan ikan beseh pangka (Apogon sp) pada ukuran $30 \mathrm{~mm}$. Lebih lanjut Sudirman et al (2012) menjelaskan bahwa dalam penelitiannya dari ketiga jenis spesies yang lolos hanya ikan teri yang dapat dikalkulasi selektivitasnya dan menunjukkan bahwa pada ukuran $21 \mathrm{~mm}$ ikan teri masih dapat lolos pada mata jaring, sedangkan udang masih lolos pada ukuran $19 \mathrm{~mm}$ dan ikan beseh lolos pada ukuran $20 \mathrm{~mm}$.

\section{KESIMPULAN}

Komposisi hasil tangkapan bagan rambo secara keseluruhan berjumlah 37.881 individu yang terdiri dari 50 spesies, masing-masing 46 spesies ikan dari 24 famili, 3 spesies cumi-cumi (mollusca), 1 spesies udang (crustacea), dan 1 spesies tidak dapat diidentifikasi. Hasil tangkapan bagan rambo didominasi oleh ikan teri (Stolephorus commersoni) sebagai hasil tangkapan utama (main catch) sebanyak $73,83 \%$, hasil tangkapan sampingan (by catch useable) sebanyak $26,13 \%$, dan hasil tangkapan yang dibuang ke laut (by catch discarded) sebanyak $0,026 \%$.

\section{DAFTAR PUSTAKA}

Akiyama, S. 1997. Discarded Catch of Set-Net Fisheries in Tateyama Bay. Journal of The Tokyo University Of Fisheries. 84(2):53-64.

Allen, G., Swainston, R., Ruse, J. 1999. Marine Fishes of Southeast Asia. A Field Guide for Anglers and Divers. 292 p.

Alverson, D.L., Freeberg, M.H., Murawski, S.A., Pope, J.G. 1994. A Global Assessment of Fisheries By Catch and Discards. FAO Fisheries 
44 Zul Chaidir et al.

JURNAL SAINS dan INOVASI PERIKANAN / Journal of Fishery Science and Innovation

Vol. 3, No. 2, 39-44, Juli 2019

and Aquaculture Technical Paper. No 339. 233 pp.

Assir, A., Palo, M., Jaya, I., Sari, R.K. 2017. Komposisi Jenis Hasil Tangkapan Bagan Perahu yang Beroperasi di Laut Flores Kabupaten Kepulauan Selayar pada Musim Angin Muson Barat. Jurnal IPTEKS PSP. 4(7): 108-111.

Cohran, W. G. 1991. Teknik Penarikan Sampel Edisi Ketiga. Jakarta: UI Press.

Dewi, N.N., Kamal, M.M., Wardianto, Y. Variasi Spasial dan Temporal Biomassa Komunitas Ikan di Perairan Pesisir Kabupaten Tanggerang Banten. Jurnal Ilmu dan Teknologi Kelautan Tropis. 8(1): 39-55.

Direktorat Jenderal Perikanan tangkap. 2005. Definisi dan Klasifikasi Statistik Perikanan Tangkap. Jakarta: Departemen Kelautan dan Perikanan. 50 hal.

Firdaus, I., Fitri, A.D.P., Sardiyatmo., Kurohman. 2017. Analisis Alat Penangkap Ikan Berbasis Code of Conduct for Responsible Fisheries (CCRF) di Tempat Pelelangan Ikan (TPI) Tawang Kendal. Indonesian Journal of Fisheries Science and Technology. 13(1): 65-74.

Gulland, J.A. and Rotschilds, B.J. 1984. Penaeid Shrimps, Their Biology and Management. Fishing News Books. Farnham. London.

Hall. S. J. 1999. The Effects of Fishing and Marine Ecosystem and Communities. Blackwell Science Ltd. London. 16-21 p.

Hasan. 2008. Uji Coba Penggunaan Lampu Lacuba Tenaga Surya pada Bagan Apung terhadap Hasil Tangkapan Ikan di Pelabuhan Ratu Jawa Barat. Jurnal Sains dan Teknologi Indonesia. 2(3): 1118.

Luasunanug, A. 2011. Analisis Musim Pennagkapan Ikan teri (Stolephorus sp.) di Teluk Dodinga Kabupaten Halmahera Barat. Jurnal Perikanan dan Kelautan Tropis. 7(1): 6-11.

Masrikat, J.A.N. 2009. Kajian Standing Stock Ikan Pelagis Kecil dan Demersal serta Hubungannya dengan Kondisi Oseanografi di Laut Cina Selatan Perairan Indonesia. Sekolah Pascasarjana. Institut Pertanian Bogor. 235 hal.

Nelwan, A.F.P., Sudirman., Nursam, M., Yunus, M.A. 2015. Produktivitas Penangkapan Ikan Pelagis di Perairan Kabupaten Sinjai pada Musim Peralihan Barat-Timur. Jurnal Perikanan. 17(1): 18-25.
Purbayanto, A. Widodo, S.H., Santosa, J., Wahyu, R.I., Dinarwan, Zulkarnain, Sarmintohadi, Nugraha, A.D., Soeboer, D.A., Pramono, B., Marpaung, A., Riyanto, M. 2004. Pedoman Umum Perencanaan, Pengelolaan dan Pemanfaatan Hasil Tangkap Sampingan Pukat Udang di Laut Arafura Provinsi Papua. Jakarta. Dinas Perikanan dan Kelautan Provinsi Papua dan PT. Sucofindo. 68 hal.

Saila, S.B. 1983. Importance and Assessment of Discards in Commercial Fisheries. FAO Fisheries Circular No 765. Food and Agriculture Organization of the United Nations. Rome. 62 pp.

Sumardi, Zainal, Sarong, M.A., Nasir, M. 2014. Alat Penangkapan Ikan yang Ramah Lingkungan Berbasis Code of Conduct for Responsible Fisheries di Kota Banda Aceh. Agrisep. 15(2):10-18.

Tirtana, D. 2016. Pengaruh Waktu Hauling terhadap Hasil Tangkapan Bagan Apung di Selat Bali. Departemen Pemanfaatan Sumberdaya Perikanan. Fakultas Perikanan dan Ilmu Kelautan. Institut Pertanian Bogor. Bogor. Skripsi. 35 hal.

Yuda, L.K., Iriana, D., Khan, A.M.A. 2012. Tingkat Keramahan Lingkungan Alat Tangkap Bagan di Perairan Pelabuhan Ratu Kabupaten Sukabumi. Jurnal Perikanan dan Kelautan. 3(3): 7-13.

Wahyu, I.R. 2008. Kajian Perikanan Trawl Demersal : Evaluasi Tiga Jenis Bycatch Reduction Device (BRD). Bogor. Pemanfaatan Sumberdaya Perairan. Fakultas Perikanan dan Ilmu Kelautan. Institut Pertanian Bogor. 207 hal. 